\title{
Robotic Distal Pancreatectomy and Splenectomy for an Intrapancreatic Hepatocellular Carcinoma: A Case Report and Review of the Literature
}

\author{
Charles C. Vining, ${ }^{1}$ Phillip J. Hsu, ${ }^{1,2}$ Darryl Schuitevoerder, ${ }^{1}$ Nora E. Joseph, ${ }^{3}$ and Melissa E. Hogg ${ }^{4, *}$
}

\begin{abstract}
Background: Liver parenchyma that resides outside of the normal hepatic confines is defined as accessory liver if in communication with the native biliary tree, or ectopic liver (EL) if it is not. EL can develop in a variety of tissues, including but not limited to the gallbladder, the hepatic ligaments, the pancreas, and retroperitoneum. EL has an increased propensity for malignant degeneration resulting in hepatocellular carcinoma (HCC).

Presentation: A 67-year-old Korean male presented with epigastric discomfort and was found to have an elevation in his transaminases. Cross-sectional imaging demonstrated a $1.3 \mathrm{~cm}$ solid mass in the body of the pancreas with features concerning for either a pancreatic ductal adenocarcinoma or pancreatic neuroendocrine tumor. Subsequent endoscopic ultrasound and fine needle aspiration demonstrated cells of epithelial origin with hepatocellular differentiation. A robotic-assisted distal pancreatectomy and splenectomy was performed with final pathology demonstrating a well-differentiated HCC.

Conclusions: EL with malignant degeneration resulting in HCC requires surgical excision. The majority of patients reported with EL resulting in HCC in the pancreas have had the tumors located in the body and tail. Therefore, definitive treatment requires distal pancreatectomy and splenectomy. Herein, we describe the presentation, workup, and definitive treatment of HCC arising in the pancreas.
\end{abstract}

Keywords: robotic, pancreatectomy, hepatocellular carcinoma

\section{Introduction}

The majority of incidentally discovered solid pancreatic lesions include pancreatic ductal adenocarcinoma (PDAC), pancreatic neuroendocrine tumors (pNETs), solid pseudopapillary tumors, metastatic deposits, and focal chronic pancreatitis. ${ }^{1}$ However, other rare solid pancreatic lesions exist and have clinical significance.

The liver, gallbladder, and biliary ductal system development begins in the 4th week of gestation from the ventral and caudal hepatic diverticulum of the foregut endoderm during organogenesis. In proximity, the ventral and dorsal pancreatic buds develop giving rise to the pancreatic head/uncinate and neck/body/tail, respectively. ${ }^{2}$ Owing to inappropriate tissue migration or altered cellular differentiation, ectopic liver (EL) parenchyma can develop in various locations. ${ }^{3}$

Hepatocellular carcinoma (HCC) is the third most common cause of cancer-related death worldwide and most typically originates in the setting of cirrhosis secondary to hepatitis, alcohol, autoimmune hepatitis, toxin exposure, nonalcoholic steatohepatitis and metabolic diseases such as Wilson's disease and hemochromatosis. ${ }^{4}$ EL has an increased propensity for malignant degeneration compared with the normal liver and is

${ }^{1}$ Department of Surgery, University of Chicago, Chicago, Illinois, USA.

${ }^{2}$ Medical Scientist Training Program, University of Chicago, Chicago, Illinois, USA.

Departments of ${ }^{3}$ Pathology and ${ }^{4}$ Surgery, NorthShore University HealthSystem, Evanston, Illinois, USA.

*Address correspondence to: Melissa E. Hogg, MD, MS, Department of Surgery, Walgreens Building, Floor 2, 2650 Ridge Road, Evanston, IL 60201, USA, E-mail: mhogg@northshore.org

(C) Charles C. Vining et al., 2020; Published by Mary Ann Liebert, Inc. This Open Access article is distributed under the terms of the Creative Commons License (http://creativecommons.org/licenses/by/4.0), which permits unrestricted use, distribution, and reproduction in any medium, provided the original work is properly cited. 
frequently unrelated to cirrhosis, viral hepatitis, or other known risk factors for HCC. ${ }^{5,6}$

Herein, we report a case of a patient who presented with indigestion and epigastric discomfort, found to have a distal pancreatic mass, treated with a robotic distal pancreatectomy and splenectomy, with final pathology demonstrating HCC.

\section{Methodology}

This report is exempt from institutional review board. Signed written consent was obtained from the patient to use details from the medical record without identifying the patient by name.

\section{Case Report}

A 67-year-old Korean male with no past medical or surgical history presented to his primary care physician with indigestion and epigastric discomfort. His physical examination was unremarkable. Laboratory assessment demonstrated a mild elevation in his hepatic transaminases (serum glutamic oxaloacetic transaminase 43, serum glutamic pyruvic transaminase 75 ), which prompted a transabdominal ultrasound. A hypoechoic $1.1 \mathrm{~cm}$ cystic mass without significant vascularity was identified in the body of the pancreas without ductal dilation (Fig. 1). A subsequent magnetic resonance imaging (MRI) of the abdomen demonstrated a $1.3 \mathrm{~cm}$ indeterminate solid mass in the pancreatic body with very subtle $\mathrm{T} 2$ hyperintensity and a very subtle hyperin-

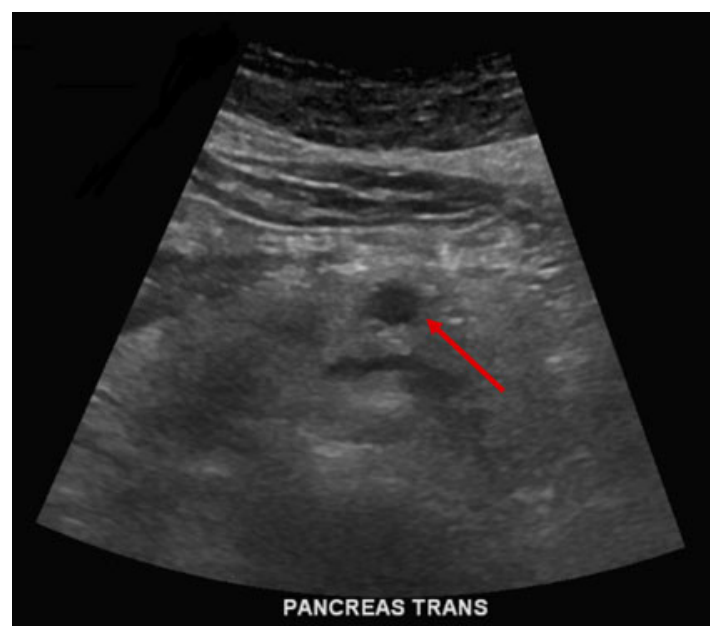

FIG. 1. Transabdominal ultrasound demonstrating a well-circumscribed hypoechoic pancreatic lesion without pancreatic ductal dilation. Red arrow denotes the lesion. tense signal on diffusion weighted images. The lesion was isointense with the background pancreatic parenchyma on postcontrast images and was suspicious for a pNET or PDAC (Fig. 2). Of note, a background of hepatic steatosis was noted. An endoscopic ultrasound with fine needle aspiration (FNA) was performed and demonstrated a hypoechoic $11.3 \mathrm{~mm}$ by $8.3 \mathrm{~mm}$ oval mass in the pancreatic body with well-defined borders (Fig. 3). Cytology from the FNA demonstrated monomorphic epithelial cells (pankeratin and cytokeratin antibody positive in a number of carcinomas [OSCAR] positivity) of hepatocellular origin (hepatocyte-specific antigen positivity) on immunohistochemistry. The Ki67 was very low to absent. These findings were consistent with a well-differentiated HCC, concerning for either metastatic or primary HCC of the pancreas. A hepatitis panel and tumor markers such as alpha-fetoprotein (AFP), carcinoembryonic antigen, and cancer antigen 19-9 were all negative.

The case was discussed in a multidisciplinary tumor board and surgical excision was recommended. Diagnostic laparoscopy demonstrated no evidence of masses in the liver and no evidence of peritoneal or omental metastasis. A total of six ports were placed and the robot was docked. An intraoperative ultrasound demonstrated that the mass was distal to the pancreatic neck. A tunnel under the neck of the pancreas at the superior mesenteric vein and portal vein confluence was established. A stapler was used to divide the pancreas immediately medial to the gastroduodenal artery. The splenic artery and vein were dissected circumferentially and divided using a linear stapler. The remaining attachments to the retroperitoneum were divided and the specimen was removed. A drain was left adjacent to the pancreatic staple line. The patient's postoperative course was unremarkable, his drain amylase level was low, and his drain was removed before discharge on postoperative day 4 .

The final gross pathology demonstrated a $1.5 \mathrm{~cm}$ tanbrown solid soft well-circumscribed lesion. Rare cells contained cytoplasmic pigment suggestive of bile. The final pathology was consistent with a $1.5 \mathrm{~cm}$ well-differentiated carcinoma with hepatoid features (Fig. 4). All margins were negative and all 18 lymph nodes evaluated were negative for carcinoma. In addition, two incidental neuroendocrine microadenomas were identified.

\section{Discussion}

Herein, we report a case of a patient with HCC in the distal pancreas, arising from EL, who underwent definitive treatment with robotic distal pancreatectomy and 

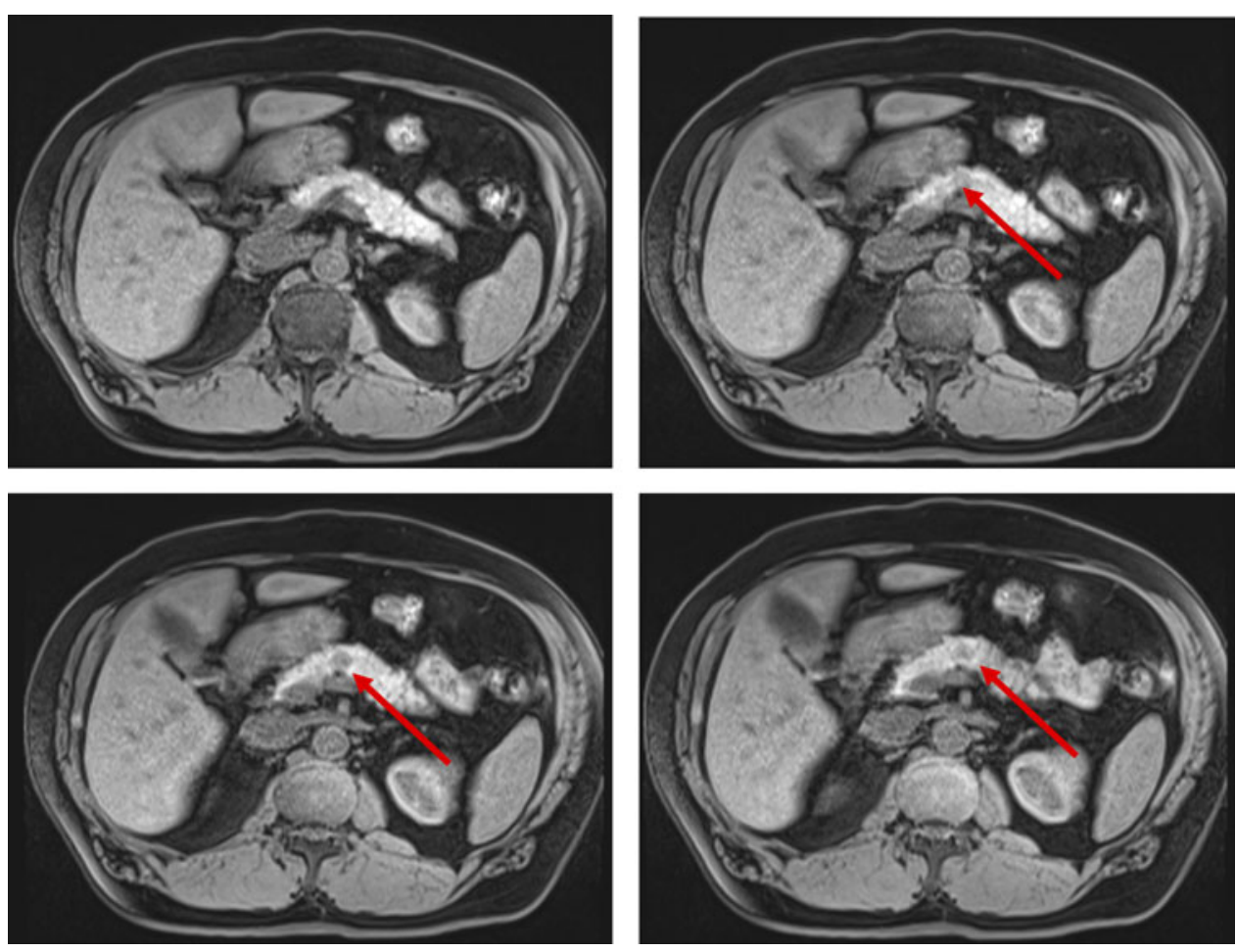

FIG. 2. Magnetic resonance imaging of the pancreatic lesion. Red arrows denote the pancreatic lesion.

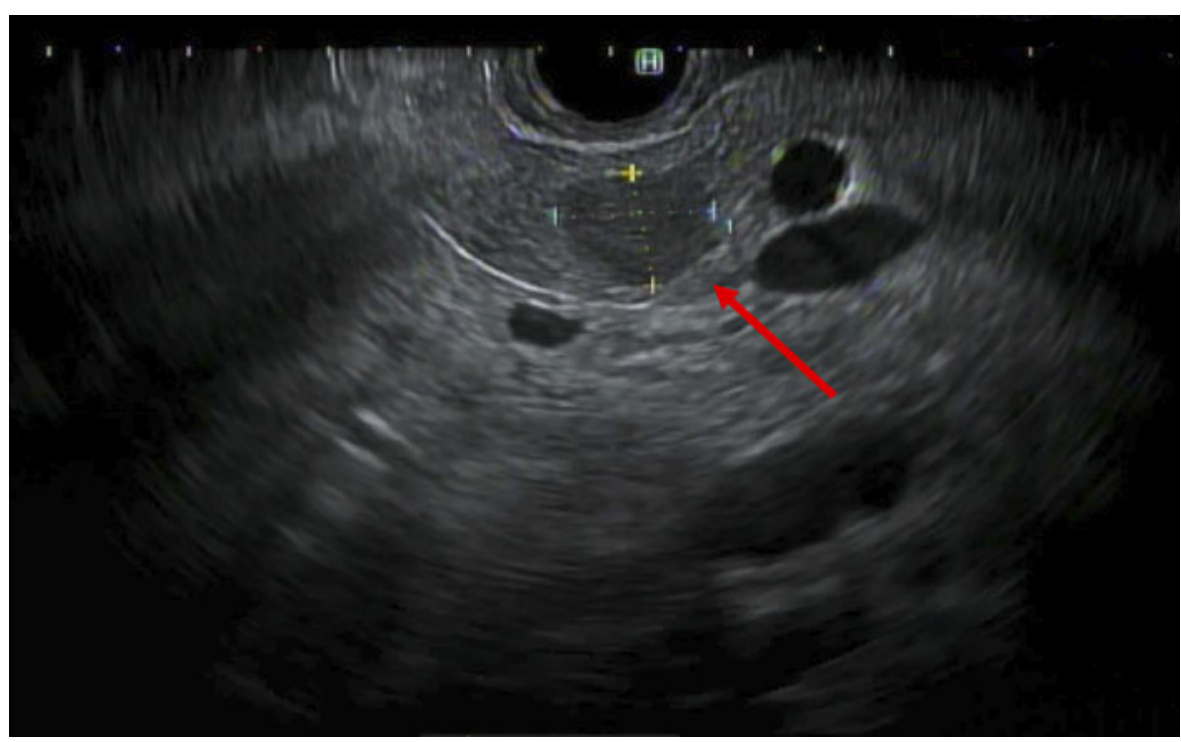

FIG. 3. Endoscopic ultrasound demonstrating a well-circumscribed hypoechoic pancreatic lesion without pancreatic ductal dilation. Red arrow denotes the pancreatic lesion. 

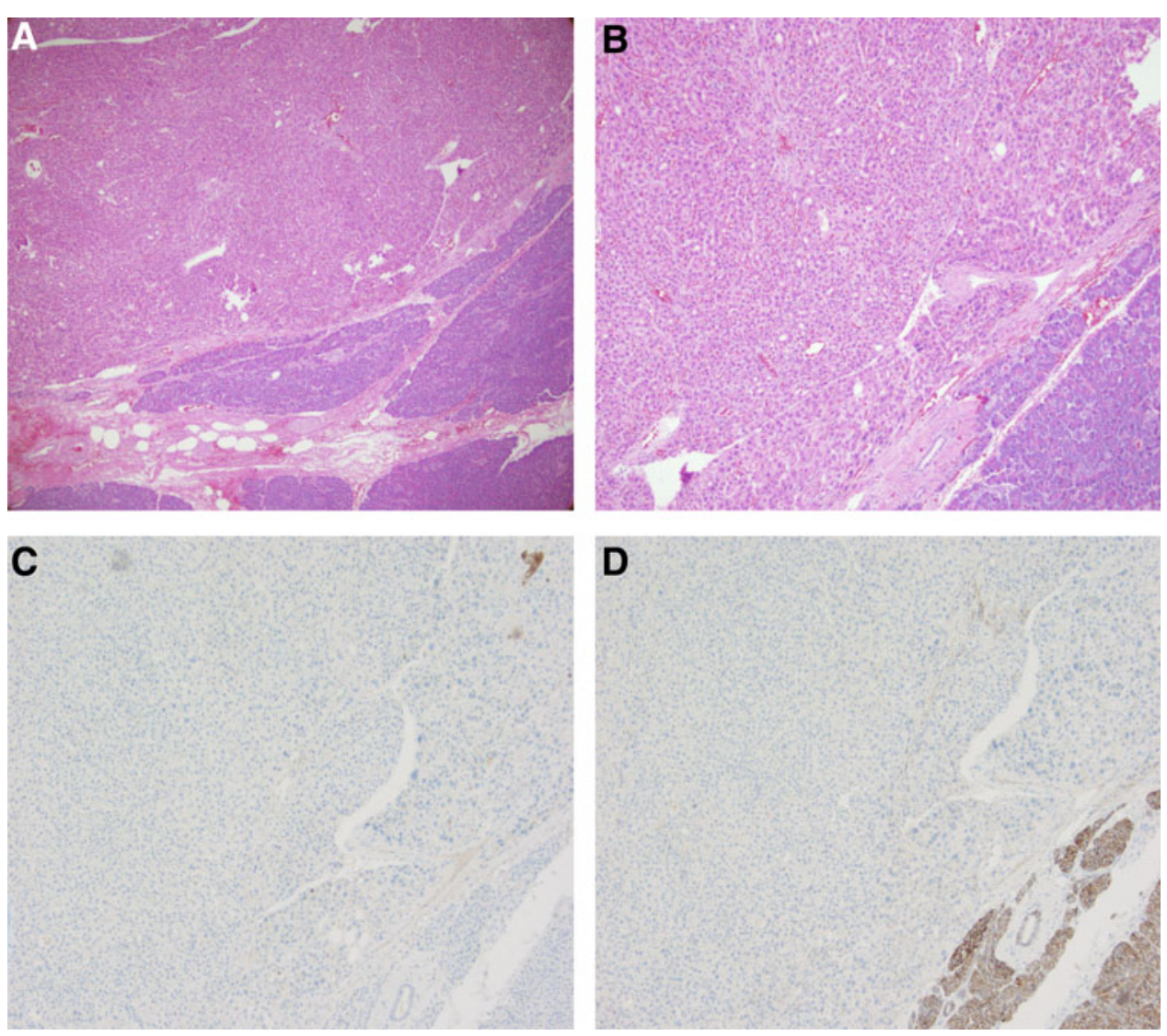

FIG. 4. Pathology of tumor and surrounding normal pancreas. (A) H\&E low power view of tumor (upper half) and normal pancreas (lower half). (B) H\&E higher power $(20 \times)$ view of the neoplastic cell population with a rim of normal pancreas, lower right-hand corner. (C, D) Immunohistochemical stains of the same field at higher power, stained with hepatocyte marker Arginase 1 (C) and epithelial marker MOC-31 (D). H\&E, hematoxylin and eosin; MOC-31, a monoclonal antibody against epithelial glycoprotein 2.

splenectomy. This case highlights the workup and treatment of a rare pancreatic lesion.

Extrahepatic tissue outside of the normal liver confines but in communication with the biliary system is defined as accessory liver, whereas extrahepatic liver tissue not in communication with the biliary system is known as EL. ${ }^{7}$ The most common location for EL is the gallbladder and can range in size from millimeters to several centimeters, ${ }^{8,9}$ whereas EL located in the pancreas is more uncommon. ${ }^{10-14}$ The exact incidence of EL is unknown but thought to be $\sim 0.24 \%$ to $0.47 \%$ (Refs. ${ }^{7,8,15,16}$ ).

EL harbors an increased risk of malignant transformation, with reported rates of $\sim 12 \%$ to $30 \%$ (Refs. ${ }^{5,17-19}$ ). This increased risk is likely due to the lack of native vasculature and inability of bile excursion. The functional impairment of the liver may cause chronic inflammation as well as prolonged exposure to carcinogenic factors due to inadequate removal. ${ }^{5,6,20}$ In addition, most patients do not have cirrhosis or the standard risk factors for HCC development. It should be noted, however, that although our patient did not have cirrhosis, the MRI did detect evidence of steatohepatitis, a risk factor for cirrhosis and subsequent HCC.

The appearance of HCC on MRI is well described and can be distinguished between a regenerative and dysplastic nodule. In the native liver, HCC demonstrates variable signal on T1-weighted precontrast images with both arterial enhancement and delayed washout. On T2-weighted images, the lesion can demonstrate an elevated signal or be isointense relative to the native liver. ${ }^{21}$ The radiological appearance of HCC in EL is less well characterized with less apparent arterial enhancement. ${ }^{5,10,22}$ The present lesion demonstrated very subtle $\mathrm{T} 2$ hyperintensity and a very subtle hyperintense signal on diffusion weighted 
Table 1. Case Reports of Primary Pancreatic Hepatocellular Carcinomas

\begin{tabular}{|c|c|c|c|c|c|c|}
\hline Study & Title & Presentation & $\begin{array}{l}\text { Pancreatic } \\
\text { location }\end{array}$ & $\begin{array}{l}\text { Tumor marker } \\
\text { elevation }\end{array}$ & Risk factors & Management \\
\hline $\begin{array}{l}\text { Adachi } \\
\text { et al. }{ }^{19}\end{array}$ & $\begin{array}{l}\text { Ectopic hepatocellular } \\
\text { carcinoma mimicking a } \\
\text { retroperitoneal tumor: a case } \\
\text { report }\end{array}$ & Incidentally found & Head & $\begin{array}{l}\text { AFP }(30.1 \mathrm{ng} / \mathrm{mL}) ; \\
\text { AFP-L3 }(83.1 \%)\end{array}$ & $\begin{array}{l}\text { Hepatitis C } \\
\text { antibody } \\
\text { positive }\end{array}$ & Extirpation \\
\hline $\begin{array}{l}\text { Braun } \\
\text { et al. }^{10}\end{array}$ & $\begin{array}{l}\text { Pure hepatocellular carcinoma } \\
\text { originates from an ectopic } \\
\text { liver nodule located in the } \\
\text { pancreas }\end{array}$ & $\begin{array}{l}\text { Abdominal } \\
\text { discomfort }\end{array}$ & Tail & No & None & Distal pancreatectomy \\
\hline Li et al. ${ }^{11}$ & $\begin{array}{l}\text { Multiple ectopic hepatocellular } \\
\text { carcinomas in the pancreas: a } \\
\text { case report }\end{array}$ & $\begin{array}{l}\text { Abdominal mass } \\
\text { and elevated AFP }\end{array}$ & $\begin{array}{l}\text { Multiple: body } \\
\text { and head }\end{array}$ & $\begin{array}{l}\text { AFP } \\
\qquad(>1200 \mathrm{ng} / \mathrm{mL})\end{array}$ & $\begin{array}{l}\text { Hepatitis B core } \\
\text { antibody } \\
\text { positive }\end{array}$ & Enucleation \\
\hline $\begin{array}{l}\text { Steen } \\
\text { et al. }^{12}\end{array}$ & $\begin{array}{l}\text { Primary hepatocellular } \\
\text { carcinoma ("hepatoid" } \\
\text { carcinoma) of the pancreas: a } \\
\text { case report and review of the } \\
\text { literature }\end{array}$ & Incidentally found & Tail & $\begin{array}{l}\text { CA 19-9 }(46 \mathrm{U} / \mathrm{mL}) \\
\text { Neuron- } \\
\text { specific enolase } \\
(16.7 \mu \mathrm{g} / \mathrm{L})\end{array}$ & None & $\begin{array}{l}\text { Distal pancreatectomy } \\
\text { and splenectomy }\end{array}$ \\
\hline $\begin{array}{l}\text { Kubota } \\
\text { et al. }^{13}\end{array}$ & $\begin{array}{l}\text { Ectopic hepatocellular } \\
\text { carcinoma arising from } \\
\text { pancreas: a case report and } \\
\text { review of the literature }\end{array}$ & Incidentally found & Tail & No & None & $\begin{array}{l}\text { Distal pancreatectomy } \\
\text { and splenectomy }\end{array}$ \\
\hline $\begin{array}{l}\text { Cardona } \\
\text { et al. }^{14}\end{array}$ & $\begin{array}{l}\text { Hepatocellular carcinoma } \\
\text { arising from ectopic liver } \\
\text { tissue in the pancreas }\end{array}$ & Back and flank pain & Body & No & Smoking & $\begin{array}{l}\text { Distal pancreatectomy } \\
\text { and splenectomy }\end{array}$ \\
\hline
\end{tabular}

AFP, alpha-fetoprotein; CA, cancer antigen.

images that can be characteristic of HCC; however, other diagnoses such as pNET remained plausible.

AFP is a protein produced by the fetal liver and functions in a similar manner to albumin. After birth, the level of this protein rapidly decreases; however, in the setting of hepatic regeneration and HCC, AFP production is re-established. Therefore, AFP is used as a tumor marker for the diagnosis of HCC and has prognostic significance. $^{23,24}$ AFP was not elevated in this case, likely due to the small size and well differentiation of the lesion. This is consistent with other reports of HCC arising in EL in the literature (Table 1). Interestingly, the fucosylated form of serum AFP, AFP-L3, which is more specific for HCC, was measured in four studies in the literature, and was elevated in all four. ${ }^{19,25-27}$

Definitive treatment of these lesions includes surgical excision and prognosis is excellent. ${ }^{5,14,20}$ Therefore, management of these lesions should mirror that of small localized HCC in the native liver without cirrhosis followed by surveillance. ${ }^{23}$ Considering the majority of pancreatic lesions are located in the distal pancreas, a minimally invasive distal pancreatectomy and splenectomy should be performed. ${ }^{28}$ The use of Sorafenib or Lenvatinib for HCC in EL has not been evaluated in cases such as ours, although it has demonstrated improved overall survival and increased time to radiological progression in advanced HCC located in the normal anatomic liver parenchyma. ${ }^{29,30}$ Considering the increased predilection for malignant degeneration in EL, routine excision of identified EL should be considered.

Primary HCC arising from EL can occur in various locations. When EL gives rise to HCC, definitive treatment is surgical excision if technically feasible. The role for adjuvant therapy is poorly defined; however, surgery, with margin negative resection, provides excellent prognosis. Further studies are required to identify risk factors for the development of HCC in EL and define risk factors for metastasis.

\section{Authors' Contributions}

All authors have approved the final article.

\section{Acknowledgments}

Dr. Melissa E. Hogg acknowledges grants from Intuitive Surgical and SAGES.

\section{Statement of Originality}

This article is original work and has not been published before and is not being considered for publication elsewhere in its final form, in either printer or electronic media.

\section{Author Disclosure Statement}

No competing financial interests exist. 


\section{Funding Information}

This research did not receive any specific grant from funding agencies in the public, commercial, or notfor-profit sectors.

\section{References}

1. Santo E, Bar-Yishay I. Pancreatic solid incidentalomas. Endosc Ultrasound. 2017;6:S99-S103.

2. Moore KL, Persaud TVN, Torchia MG. The Developing Human: Clinical Oriented Embryology. Philadelphia, PA: Saunders/Elsevier, 2008.

3. Curtis LE, Sheahan DG. Heterotopic tissues in the gallbladder. Arch Pathol. 1969;88:677-683.

4. Mittal S, El-Serag HB. Epidemiology of hepatocellular carcinoma: consider the population. J Clin Gastroenterol. 2013;47:S2-S6.

5. Arakawa M, Kimura Y, Sakata K, et al. Propensity of ectopic liver to hepatocarcinogenesis: case reports and a review of the literature. Hepatology. 1999;29:57-61.

6. Caygill CPJ, Gatenby PAC. Ectopic liver and hepatocarcinogenesis. Eur J Gastroenterol Hepatol. 2004;16:727-729.

7. Collan Y, Hakkiluoto A, Hastbacka J. Ectopic liver. Ann Chir Gynaecol. 1978;67:27-29.

8. Watanabe M, Matsura T, Takatori Y, et al. Five cases of ectopic liver and a case of accessory lobe of the liver. Endoscopy. 1989;21:39-42.

9. Lundy J, Johnson E, Edwards K, et al. Laparoscopic management of gallbladder-associated ectopic liver. JSLS. 2005;9:485-487.

10. Braun M, Kuncman W, Teresiński L, et al. Pure hepatocellular carcinoma originates from an ectopic liver nodule located in the pancreas. Wspolczesna Onkol. 2017;21:311-314.

11. Li Z, Wu X, Wen T, et al. Multiple ectopic hepatocellular carcinomas in the pancreas: a case report. Med (United States). 2017;96:1-5.

12. Steen S, Wolin E, Geller SA, et al. Primary hepatocellular carcinoma ("hepatoid" carcinoma) of the pancreas: a case report and review of the literature. Clin Case Reports. 2013;1:66-71.

13. Kubota K, Kita J, Rokkaku K, et al. Ectopic hepatocellular carcinoma arising from pancreas: a case report and review of the literature. World J Gastroenterol. 2007;13:4270-4273.

14. Cardona D, Grobmyer S, Crawford JM, et al. Hepatocellular carcinoma arising from ectopic liver tissue in the pancreas. Virchows Arch. 2007;450:225-229.

15. George NE, Raghavapuram S, Banerjee D, et al. Ectopic Hepatocellular Carcinoma within a Choledochal Cyst Diagnosed Using Single-Operator Digital Cholangioscopy. Am J Gastroenterol. 2017;112:1347-1348.

16. Martínez-Acitores D, Hernández Ainsa M, Cortés García L, et al. Ectopic hepatocellular carcinoma arising from the peritoneum. Rev Esp Enferm Dig. 2019;111:809-811.

17. Seo UH, Lee HJ, Ryu WS, et al. Laparoscopic resection of a hepatocellular carcinoma arising from an ectopic liver. Surg Laparosc Endosc Percutaneous Tech. 2008;18:508-510.

18. Aarås AM, Reitan-Gjersøe TA, Waage A, et al. Laparoscopic resection of recurrent ectopic hepatocellular carcinoma: a case report with review of the literature and guidelines for follow-up. Int J Surg Case Rep. 2015;17:92-95.
19. Adachi $Y$, Hayashi $H$, Yusa $T$, et al. Ectopic hepatocellular carcinoma mimicking a retroperitoneal tumor: a case report. World J Gastroenterol. 2020;26:2268-2275.

20. Le Bail B, Carles J, Saric J, et al. Ectopic liver and hepatocarcinogenesis. Hepatology. 1999;30:585-586.

21. Arif-Tiwari H, Kalb B, Chundru S, et al. MRI of hepatocellular carcinoma: an update of current practices. Diagnostic Interv Radiol. 2014;20:209-221.

22. Kim KA, Park CM, Kim CH, et al. Hepatocellular carcinoma in an ectopic liver: CT findings. Eur Radiol. 2003;13(Suppl. 4):L45-L47.

23. Song PP, Xia JF, Inagaki $Y$, et al. Controversies regarding and perspectives on clinical utility of biomarkers in hepatocellular carcinoma. World J Gastroenterol. 2016;22:262-274.

24. Ma W-j, Wang H-y, Teng L-s. Correlation analysis of preoperative serum alpha-fetoprotein (AFP) level and prognosis of hepatocellular carcinoma (HCC) after hepatectomy. World J Surg Oncol. 2013;11:212.

25. Nakamura N, Irie T, Tanaka S, Arii S. A case ectopic hepatocellular carcinoma with peritoneal dissemination. J Japanese Soc Gastroenterol. 2013; 110:1968-1975.

26. Fukuda SI, Yano K, Ohata K, et al. A case of ectopic hepatocellular carcinoma. J Japanese Soc Gastroenterol. 2009;106:1770-1777.

27. Shigemori $M$, Kondo $M$, Azechi $H$, et al. A case of ectopic hepatocellular carcinoma in the jejunum. J Gastroenterol. 2006;41:913-918.

28. Asbun HJ, Moekotte AL, Vissers FL, et al. The Miami International Evidence-based Guidelines on Minimally Invasive Pancreas Resection. Ann Surg. 2020;271:1-14.

29. Rimassa L, Santoro A. Sorafenib therapy in advanced hepatocellular carcinoma: the SHARP trial. Expert Rev Anticancer Ther. 2009;9:739745.

30. Kudo M, Finn RS, Qin S, et al. Lenvatinib versus sorafenib in first-line treatment of patients with unresectable hepatocellular carcinoma: a randomised phase 3 non-inferiority trial. Lancet. 2018;391:1163-1173.

Cite this article as: Vining CC, Hsu PJ, Schuitevoerder D, Joseph NE, Hogg ME (2020) Robotic distal pancreatectomy and splenectomy for an intrapancreatic hepatocellular carcinoma: a case report and review of the literature, Journal of Pancreatic Cancer 6:1, 96-101,

DOI: 10.1089/pancan.2020.0009.

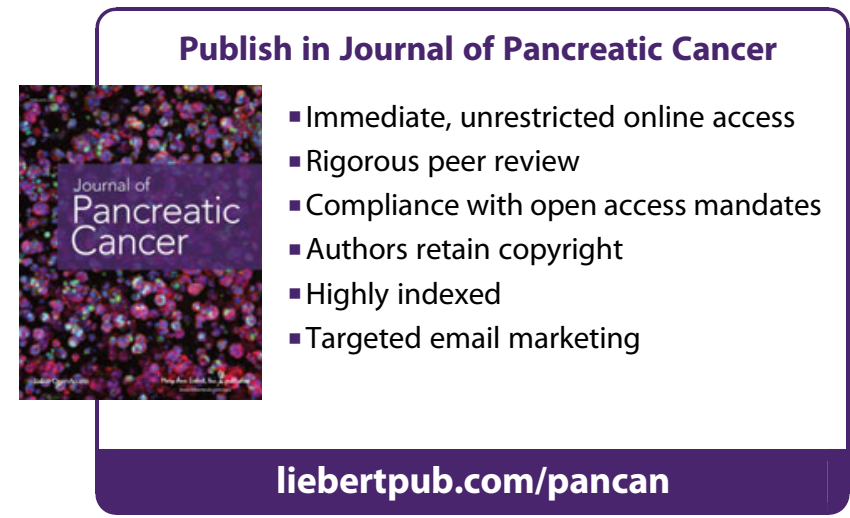

